\title{
Day-to-day tuning of the Tokaido Shinkansen timetable - carried out for every single operating hour throughout the year
}

\author{
H. Ogawa, S. Kawai, Y. Kojima, M. Goto \& H. Shoji \\ Central Japan Railway Company, Japan
}

\begin{abstract}
This paper introduces key concepts used to formulate day-to-day scheduling of the Tokaido Shinkansen, the main transportation artery linking Japan's principal metropolitan areas of Tokyo, Nagoya, and Osaka operated by the Central Japan Railway Company (JR-Central). In order to schedule train services so that passengers can always reserve a seat smoothly, we adjust the number of services for every single operating hour throughout the year, by adding extra services in addition to regular services to meet the demand of passengers, based on the detailed demand forecast. In addition, we analyze unsatisfied and potential needs by keeping a close eye on ticket sales information. For example, ticket sales progress is used to tell us whether the sales were quick or slow. Quick and good sales are an indication of strong potential needs. We add extra services promptly when the sales are faster than expected. If the Shinkansen is crowded with few seats available, it would be inconvenient and uncomfortable for passengers. Furthermore, even when there are travellers who would choose the Shinkansen if a ticket were available, we may lose the opportunity to serve them if there are no seats to sell. Therefore, we at JR-Central aim to respond to passenger needs, suppress congestion, and avoid fully-booked-up situations. As above, this paper focuses on the measures taken to avoid congestion and maintain efficient and smooth transport services for passengers. Minute and flexible tuning of timetables, along with scrupulous and expeditious scheduling approaches, is a feature of the Tokaido Shinkansen, the most densely scheduled high-speed railway in the world, operating up to 12 train runs per hour per direction and more than 370 train runs per day and serving approximately 410 thousand passengers a day.
\end{abstract}

Keywords: Tokaido Shinkansen, timetable, scheduling, extra services, threshold level, stress index, sales progress curve, demand forecast. 


\section{Introduction}

Thr Central Japan Railway Company commenced operations in April 1987 upon the privatization and break-up of the Japanese National Railways (JNR). The core of JR Central's operations is the Tokaido Shinkansen, the main transportation artery linking Japan's principal metropolitan areas of Tokyo, Nagoya, and Osaka. While JR Central's operating area covers just $23.7 \%$ of Japan's land area, it accounts for $58.4 \%$ of the country's population and $63.4 \%$ of the gross domestic product.

The major characteristics of the Tokaido Shinkansen include its safety, reliability, high speed, high volume of train runs, environmental adaptability, low energy consumption, and low cost. As regards the high volume performance, the Tokaido Shinkansen is the most densely scheduled high-speed railway in the world, operating up to 12 train runs per hour per direction and more than 370 train runs per day and serving approximately 410 thousand passengers a day.

The Tokaido Shinkansen consists of three types of trains: from the fastest to the slowest, they are Nozomi, Hikari, and Kodama, all of which having different stopping patterns. Nozomi, which is for long haul passengers, arrives and departs from Tokyo and stops at major stations: from east to west, they are Shinagawa, Shin-Yokohama, Nagoya, Kyoto, and Shin-Osaka (distance of approximately $550 \mathrm{~km}$ from Tokyo). Many Nozomi services continue onward to the SanyoShinkansen operated by JR-West, going as far as Hakata (distance of approximately $1170 \mathrm{~km}$ from Tokyo). On the other hand, Hikari stops at intermediate stations as well. Kodama stops at all stations.

As regards the basic patterned schedule for an hour, there are eight Nozomi, two Hikari, and two Kodama services per one direction. Almost all of the Hikari and Kodama are daily services, but not all of the eight Nozomi services are regular. Some of them are extra services, which will be operated when there is much demand. In particular, JR-Central is controlling the number of Nozomi services from three to eight for every single operating hour of 365 days, precisely forecasting and closely monitoring the passengers' demand.

This paper will mainly focus on the scheduling process of Nozomi services, used by the majority of passengers travelling between major cities of Tokyo, Nagoya, and Osaka. The length of train is approximately $400 \mathrm{~m}$ with 16 cars. The train consists of 3 first class cars with 200 seats, 10 reserved coach class cars with 873 seats, and 3 non-reserved coach class cars with 250 seats.

\section{What was the problem?}

"Trains are fully booked up." Is this a good situation? JR Central does not think so. We at JR Central aim to schedule train services so that passengers can always reserve a seat smoothly. Some might argue that a railway operator should pursue selling all the seats and limit the supply to the level whereby the majority of train seats are expected to be sold. If only filling trains were the goal, this would be easy - it could be achieved simply by reducing the number of train runs. Our goal is, however, not so. What we aim at is to have travellers choose the Tokaido 
Shinkansen as a means of transportation and to maintain and increase the number of such customers in the long run.

If the Shinkansen is always fully booked, it would be inconvenient and uncomfortable for passengers. Furthermore, even when there are travellers who would choose the Shinkansen if a ticket were available, we may lose the opportunity to serve them if there are no seats to sell. That is, to try to keep trains full could work to reduce room for an increase in number of passengers.

Another point to consider is the threat of competitors. If passengers were constantly exposed to fully booked trains, we would face the risk that passengers might switch their transportation modes. Supply shortage of transport services in the market also encourages airlines to increase the number of their flights, since they can easily fill their aircraft with passengers overflowing from the Shinkansen without need to discount their fares.

\begin{tabular}{|c|c|c|c|c|c|c|}
\hline \multicolumn{2}{|c|}{$\begin{array}{c}\text { East Bound from } \\
\text { Shin-Osaka } \\
9: 34\end{array}$} & \multicolumn{2}{|c|}{ Coach } & $\begin{array}{c}\text { To } \\
\text { Nagoya }\end{array}$ & \multirow{2}{*}{$\begin{array}{c}\text { To } \\
\text { Shin-Yokohama } \\
\text { F C C } \\
\end{array}$} & \multirow{2}{*}{ 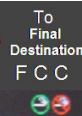 } \\
\hline Train Numbe & & Destinatic & Departure & 93 & & \\
\hline NOZOMI & 6 & TOKYO & $9: 37$ & 000 & 000 & 000 \\
\hline HIKARI & 366 & TOKYO & $9: 40$ & 000 & 000 & 000 \\
\hline NOZOMII & 122 & TOKYO & $9: 47$ & 000 & 000 & 000 \\
\hline NOZOHI & 170 & TOKYO & $9: 53$ & 000 & 000 & 000 \\
\hline NOZOWI & 8 & TOKYO & $10: 00$ & $0-0$ & $0-0$ & $0-0$ \\
\hline NOZOMI & 124 & TOKYO & 10:07 & 000 & 000 & 000 \\
\hline HIKARI & 412 & TOKYO & $10: 13$ & 000 & 000 & 000 \\
\hline NOZOHI & 78 & TOKYO & $10: 17$ & 000 & 000 & 000 \\
\hline NOZOMI & 10 & TOKYO & $10: 37$ & 000 & 000 & 000 \\
\hline KODAM & 546 & 0 & $0.5 n$ & & & \\
\hline KODAMA & 550 & TOKYO & $10: 50$ & 000 & 000 & 000 \\
\hline
\end{tabular}

Figure 1: Availability display (All the trains are available).

\begin{tabular}{|c|c|c|c|c|c|}
\hline \multirow{2}{*}{\multicolumn{2}{|c|}{$\begin{array}{c}\text { West Bound from } \\
\text { Tokyo } \\
17: 35 \\
\text { Train Number }\end{array}$}} & \multirow{2}{*}{ Destination Departure } & \multirow{2}{*}{$\begin{array}{c}\text { To } \\
\text { Nagoya } \\
\text { F C C } \\
\text { (3) }\end{array}$} & \multirow{2}{*}{$\begin{array}{c}\text { To } \\
\text { shin-0saka } \\
\text { F C C } \\
9 \Theta \\
\end{array}$} & \multirow{2}{*}{$\begin{array}{c}\text { To } \\
\text { Final } \\
\text { Destination } \\
\text { FC C } \\
\Theta \Theta \\
\end{array}$} \\
\hline & & & & & \\
\hline NOZOMI & 135 & SHIN-OSAKA 17:40 & $x \times x$ & $x \times x$ & \\
\hline NOZONI & 81 & HIROSHIMA 17:50 & $x \times x$ & $\times \times x$ & $x \times x$ \\
\hline NOZOMI & 139 & SHIN-OSAKA $18: 00$ & $x \times x$ & $x \times x$ & --- \\
\hline HIKARI & 383 & OKAYAMA $18: 03$ & $x \times x$ & $x \times x$ & $x \times x$ \\
\hline NOZONI & 51 & HAKATA $18: 10$ & $x-x$ & $x-x$ & $x-x$ \\
\hline NOZOMI & 195 & OKAYAMA $18: 13$ & $0 \times x$ & $0 \times x$ & $0 \times x$ \\
\hline NOZOMI & 143 & SHIN-0SaKa $18: 20$ & $0 \times x$ & $0 \times x$ & --- \\
\hline NOZOMI & 83 & HIROSHIMA $18: 30$ & $O \times x$ & $0 \times x$ & $O \times x$ \\
\hline HIKARI & 425 & SHIN-OSAKA $18: 33$ & $x \times x$ & $x \times x$ & --- \\
\hline $\begin{array}{l}\text { KODAMA } \\
\text { KODAMA }\end{array}$ & $\begin{array}{l}577 \\
570\end{array}$ & IACOYA 17:56 & Oxx & --- & --- \\
\hline
\end{tabular}

Figure 2: $\quad$ Availability display (most trains are full).

An availability display as shown in fig. 1 and fig. 2 are placed at JR-Central's Schedule planning section to monitor the sales constantly. It shows the availability of every train for each destination. The Schedule planning section is committed to contrive ways to avoid all-booked-up situation as in Fig. 2. 


\section{Solution to this problem}

\subsection{Economies of scale}

Crowded trains with few seats available can be compared to restaurants with scarce stock of kitchen material to cook. Reducing the supply of services may bring the operating cost down slightly, but on the other hand we would lose some of our business opportunities and market share in the long run. To address this subject, we provide additional train services flexibly up to a certain level that meets demand fluctuation of Shinkansen passengers. In other words, we carefully estimate hourly travel demands and constantly control the supply to avoid the "all-booked-up" situation.

The key feature of railway industry is its relatively low operating cost compared to the huge fixed cost. In other words, either increasing or decreasing the number of services has a limited effect on the total cost.

As shown in fig. 3, the fixed cost is relatively high compared to variable cost in industry A. On the other hand, variable cost constitutes a large part in industry B. Since JR-Central owns varieties of fixed facilities such as stations, rolling stocks, and infrastructure, whose expenditures do not change in proportion to the activity of a business, the fixed cost of running the Shinkansen covers a large part of the total cost. Therefore, the cost structure of the rail business like JRCentral can be classified as industry A. In this case, marginal cost of extra services or production of goods is relatively smaller for industry A than B.

Therefore, if we want to take advantage of this characteristic, we should achieve economies of scale by running more trains rather than reducing our services, as long as demand exceeds supply.

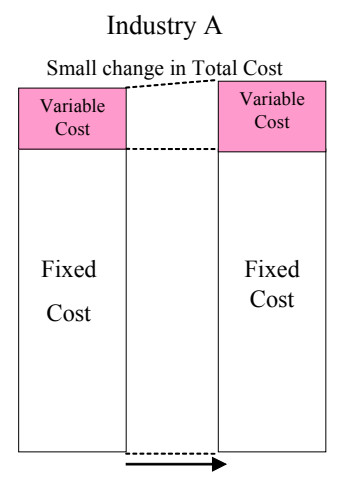

Increase Production by $10 \%$
Industry B

Big change in Total cost

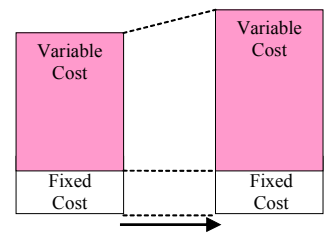

Increase Production by $10 \%$

Figure 3: $\quad$ Cost structure of industry A and B.

\subsection{Tuning the hourly departures of trains}

\subsubsection{Finding threshold levels of total acceptable hourly passengers}

Firstly, we have analyzed the adequate number of train runs in a given one-hour period to avoid the "all-booked-up" situation. Our goal is to provide train 
services up to the point where at least some of the trains in a given one-hour period still have some available seats for passengers. Tokaido Shinkansen has the following three accommodations; first class, reserved coach class, and nonreserved coach class. Since the reserved coach class secures passenger's seat for a relatively reasonable fare, the majority of passengers choose this type of accommodation. Therefore, our research focuses mainly on avoiding the "allbooked-up" situation of reserved coach class. Our analysis shows that the total number of hourly passengers using the reserved coach class reaches its peak depending on the total number of train services and passengers in a given onehour period.

Fig. 4 shows how passengers of a certain train are distributed to first class, reserved coach, and non-reserved coach class. The horizontal axis is the total number of passengers. The vertical axis is the number of passengers distributed to different accommodations. This figure shows that the number of passengers of each accommodation rise steadily until the reserved coach class reaches its peak. After this point, first class and non-reserved coach class will sharply increase because of the fully-booked-up of reserved coach.

Based on this model, the linkage between the number of hourly reserved coach passengers and the peaking point for each number of train services is shown in fig. 5. In other words, the figure gives threshold levels of total number of acceptable hourly passengers depending on the number of train services to avoid all-booked-up situation. For example, reserved coach class of a given onehour period will be completely full if the total number of hourly passengers exceeds "b" with five services per hour.

If this happens, it becomes more difficult to accommodate additional passengers to the reserved coach class. In other words, most train's coach class seats are fully booked in this situation. On the other hand, if we increase the number of services as the number of passengers of reserved coach class is about

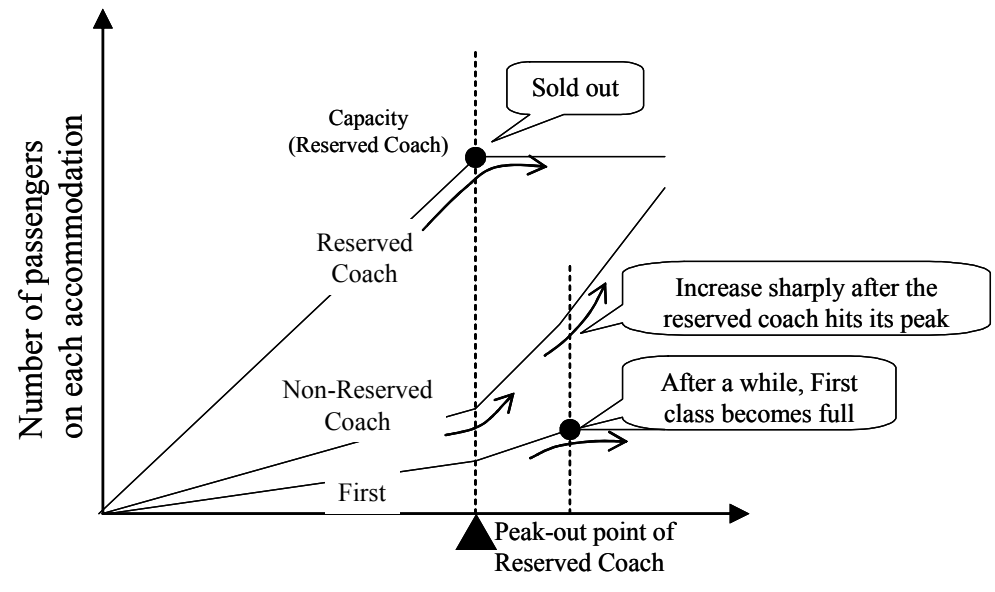

Total number of passengers

Figure 4: Distribution of passengers of single service. 


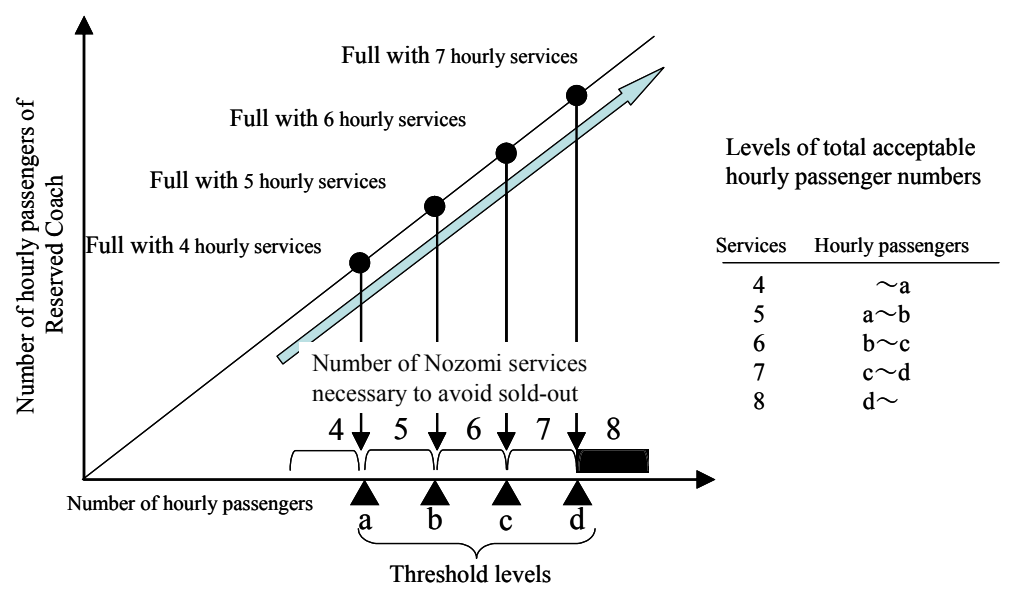

Figure 5: Threshold levels to avoid all-booked-up.

to hit its peak, we can avoid the sold-out situation. In the case mentioned above, we have to add train services up to six trains per hour to accommodate coach passengers. But this only works up to "c". If the total number of hourly passengers exceeds "c", we have to add another service.

Thus, the analysis gives threshold levels of total acceptable hourly passenger numbers depending on the number of train services to avoid all-booked-up situation. If the number of hourly passengers for all the accommodations is less than the threshold level, at least some of the trains in a given one-hour period still have available seats for additional passengers. Viewed from another side, the threshold levels give us the necessary number of train services to avoid the "allbooked-up" situation. These threshold levels are calculated statistically for all the train numbers.

\subsubsection{Tuning the number of services to demand fluctuation}

In fact, based on the detailed demand forecast, we adjust the number of services for every single operating hour throughout the year, by adding extra train services in addition to regular services to satisfy the demand of passengers.

For example, fig. 6 shows the difference of train runs in eight consecutive days with three-day weekend. Horizontal axis is the hours of the trains departing Tokyo. Each block represents a train service. White blocks are daily services and dark-shaded blocks are extra services. These figures indicate that the number of services changes dramatically on a daily basis to accommodate fluctuating travel demands. Especially during the three-day weekend, there are many extra services on the first and the last day to accommodate the vacationers.

Another example is shown in fig. 7. The electrocardiographically shaped graph is the day-to-day variation of the number of services from July, 2008 to September, 2008. Generally, Fridays are at the peak for almost every week. On the other hand, Saturdays and Sundays are at the bottom. Since the majority of passengers ride Shinkansen for business trips, numbers of hourly departures are entirely different from weekdays to weekends. 


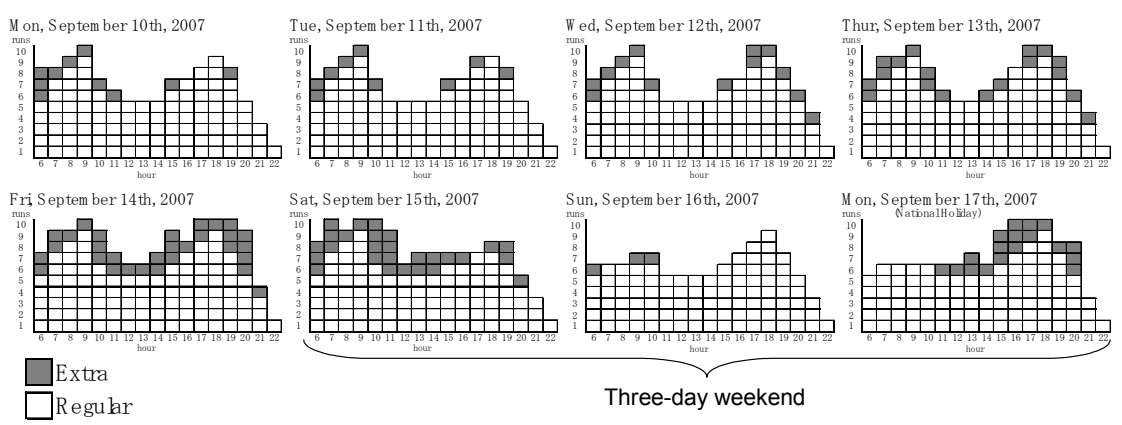

Figure 6: Number of hourly Nozomi and Hikari services departing Tokyo (westbound services).

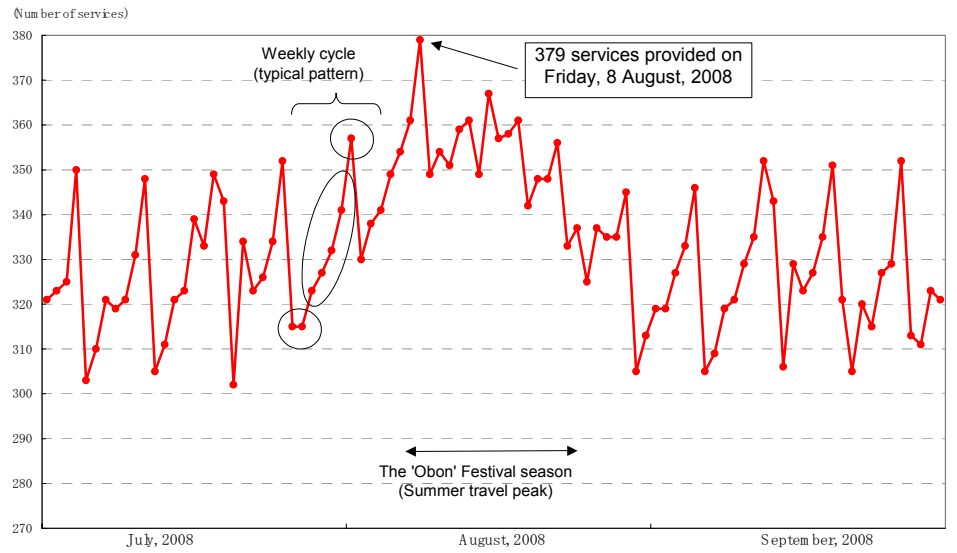

Figure 7: Number of day-to-day services.

\subsection{Responding to hidden demand}

As mentioned above, basic processes of the demand forecast and tuning of the hourly departures of trains are based on the actual number of passengers using the Tokaido Shinkansen in the past. For example, we estimate the future demands of subsequent year using the actual numbers of this year. These processes are essential in railway business, but we go further than that. In addition to tuning the number of services minutely and dynamically for every single hour of 365 days, we also devote our energy on analyzing the potential and unsatisfied needs of Shinkansen passengers.

The experience of a staff member who used to work at the ticketing office caused us to reflect upon focusing the unsatisfied and potential needs of customers. He was always at all sorry for customers when he was not able to sell the tickets of trains at capacity. Learning from the past experience, he was filled with sense of mission to tune the numbers of services to avoid the sold-out condition. Moreover, he was sensing that services at the same capacity rate cannot be treated equally. In other words, sales of one service can be very quick 
and the other can be slow. Also, he knew that degree of unsatisfied needs differs from one train to another even in the case that both services are at their capacity. On the basis of this concept, we focus on the processes of sales, in addition to closely monitoring the final outcome.

\subsubsection{Developing stress index}

We have analyzed unsatisfied and potential needs by keeping a close eye on ticket sales information. Ticket sales progress is not only used to show how many seats were finally sold, but also used to tell us whether the sales were quick or slow. Quick and good sales are an indication of strong potential needs. The newly developed "stress index", which visualizes the passengers' stress by summation of the unsatisfied needs, can be used to practically formulate scheduling of the Tokaido Shinkansen with reduced stress on passengers.

The newly developed "stress index" is developed from sales data from Multi Access seat Reservation System (MARS). It is the JR's nationwide ticketing and reservation system installed in ticketing offices and travel agencies. Ticket windows equipped with MARS sell tickets for all JR trains with reserved seats beginning one month prior to the ride. The host computer of MARS manages the sales information of all the JR-group trains including the Tokaido Shinkansen.

In addition to selling tickets, this system collects the following two types of sales data. One is the level of "YES", and the other is level of "NO". "YES" is the total number of passengers the MARS was able to sell tickets at their request. On the other hand, "NO" represents the number of passengers whose request was not met. These numbers are collected daily for all the Tokaido Shinkansen trains.

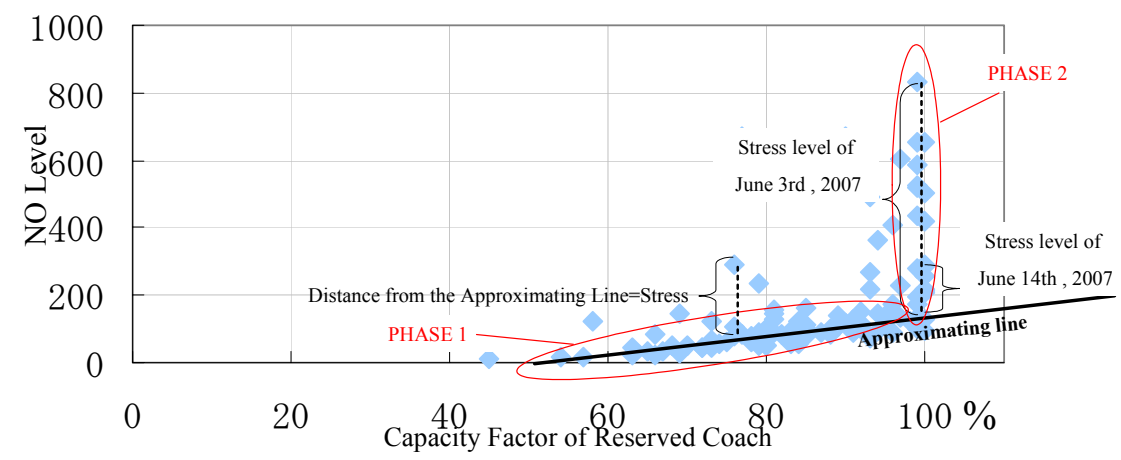

Figure 8: $\quad$ Stress index of a Nozomi (sample plots of a Nozomi Train).

We have plotted the capacity factor as X-axis position and level of "No" as Y axis position of a specific train for all the running days, as shown in fig. 8. As marked phase 1 in the figure, we can observe the phenomenon that the "NO" levels increase steadily from capacity factor of $50 \%$ or above. Also as indicated in phase 2, "NO" levels increase sharply as the capacity factor comes close to $100 \%$. The "NO" levels on phase 2 are caused by the sold-out of the seats. Meanwhile, those on phase 1 are caused by not meeting passengers' request such 
as smoking and window-aisle preferences. And the "NO" levels are relatively acceptable and inevitable on phase 1 rather than on phase 2 . Therefore, the stress index is calculated from the distance between "NO" levels and approximating line of phase 1 . The feature of this index is that the stress will increase as the number of passengers whose request was not met grows, under the condition of high capacity factor. Also, the Stress index reveals the level of unsatisfied and potential needs as shown in fig. 8. For example, although the capacity factor is almost same for both June $3^{\text {rd }}$ and, $14^{\text {th }}$, the stress level is higher on $3^{\text {rd }}$ than on $14^{\text {th }}$. Therefore we can say that the unsatisfied and potential need very high on June $3^{\text {rd }}$.

\subsubsection{Monitoring sales process}

Moreover, sales information is used to respond to unexpected special demands which could not be forecasted in the day-to-day scheduling process performed several months in advance.

Fig. 9 shows the sale processes of trains in a given one-hour period. The $\mathrm{X}$ axis is the remaining days until departure and the $\mathrm{Y}$ axis is the cumulated number of seats sold. The bold curve is the sales progress path of this year. On the other hand, the dotted curve is the projected sales generated from the past records. If the bold curve is way above the dotted curve as shown in the figure, the graph indicates fast sale and the sales may reach its capacity. For example, this may happen during fall and cherry blossoms seasons when we can't accurately predict the timing of foliage and full bloom. During these seasons, many tourists travel to Kyoto to see the foliage and cherry blossoms. Also we see this phenomenon when unexpected special events such as big concerts and footballs games are held along the Shinkansen line, increasing the number of passengers. Under these circumstances we have to add extra services to accommodate passengers' needs. Therefore, in order to respond to unexpected special demands, we carefully observe whether the sales are faster than was expected, to determine if extra services should be added.

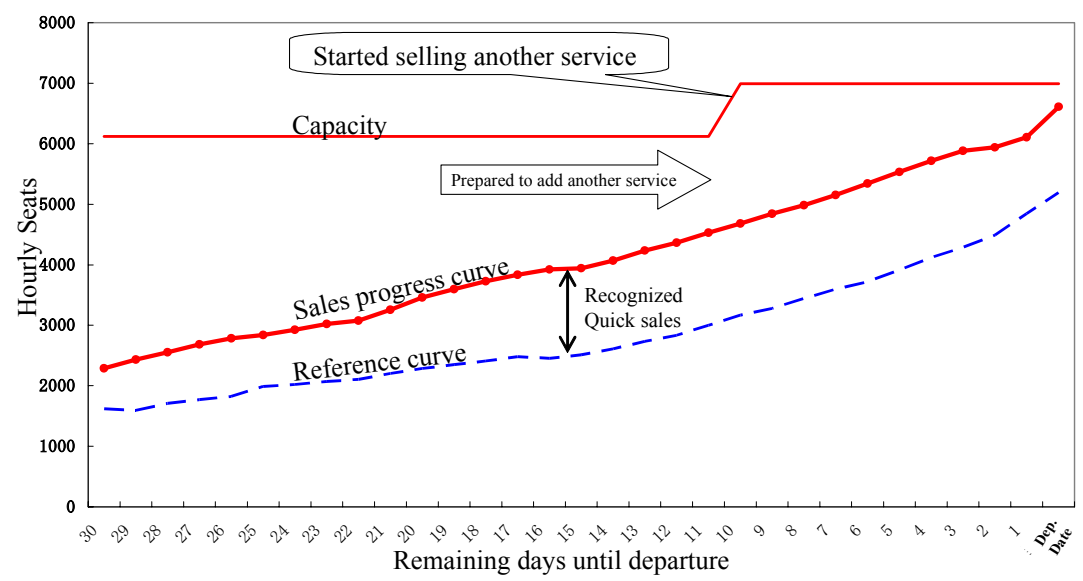

Figure 9: $\quad$ Sales process curve of reserved coach class. 


\section{Conclusions}

Implementing the approaches described in this paper in a practical manner, JRCentral has strived to increase extra services added on top of regular services, with the aim of responding to passenger needs, suppressing congestion, and avoiding 'fully-booked-up' situation. The number of the extra services alone has aggregated to more than 13,000 in the fiscal year ended March 2008.

Those looking into the line's timetable will easily find that many services have remarks showing days of running, which seemingly are a mere enumeration of digits, but actually are the outcome of highly statistical calculations and scrupulous scheduling. Furthermore, the train graph of the Tokaido Shinkansen varies greatly from day to day and the numbers of hourly departures are tuned minutely and dynamically for every single hour of 365 days. Such operational flexibility, enabling the line to accommodate fluctuating travel demands, can be viewed as a latent, but significant feature of the Tokaido Shinkansen.

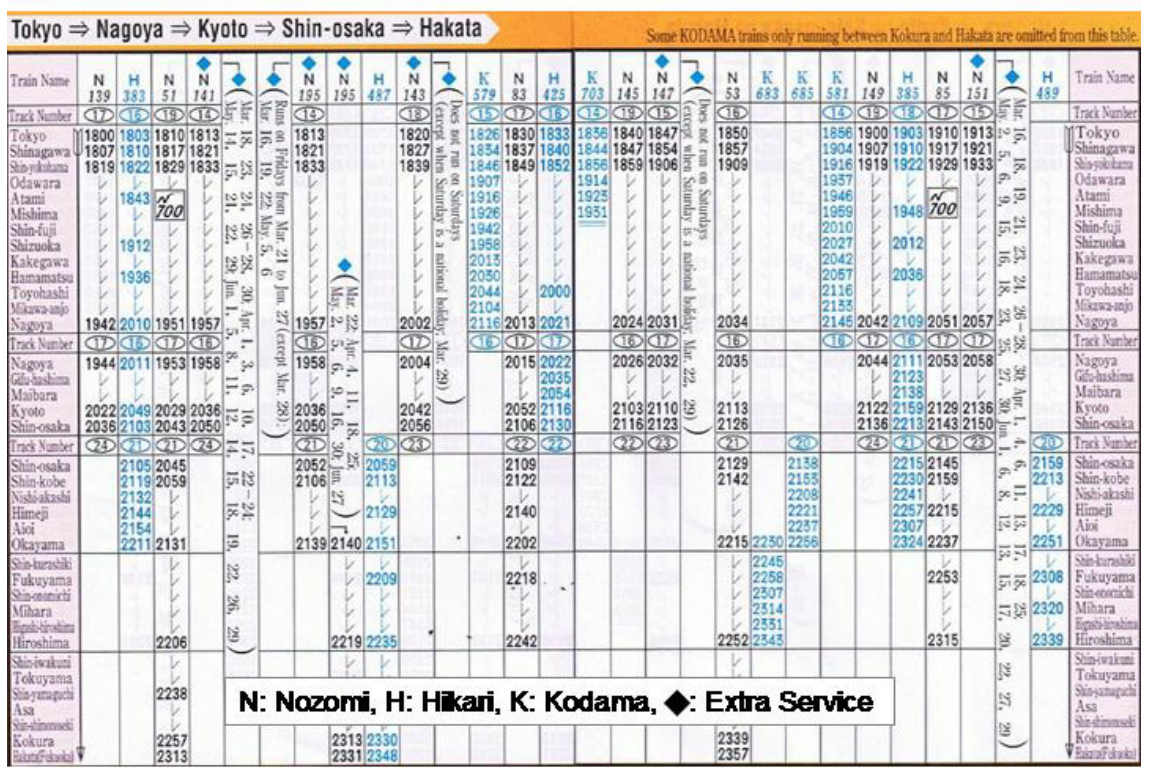

Figure 10: Timetable of the Tokaido Sanyo Shinkansen.

\section{References}

[1] Kojima, Y., Kawai, S., and Sato, T., Tuning of Tokaido Shinkansen timetable-what made us to operate more than 310 trains per day, JREA, Volume 49, Number 8, pp. 31825-31829, August, 2006

[2] Kojima, Y. and Sato, T., Tuning of Tokaido Shinkansen-operating more than 10,000 extra services a year, Japan Train Operation Association (JTOA Monthly), Volume 561, pp. 9-13, March, 2006

[3] Central Japan Railway Company Webpage, http://english.jr-central.co.jp 